\title{
Study of Flip Classroom Instructional Design in College English
}

\author{
Qinghua Peng \\ Department of Foreign Languages, Gannan Normal University, Jiangxi \\ Province, Ganzhou, 341000, China
}

\begin{abstract}
Flipping classroom realize the optimization of teaching effect by changing the teaching process of knowledge transfer and knowledge internalization, provides a new idea for the reform of college English teaching. Based on the theory of constructivism and mastery of learning, this paper puts forward the instructional design flow of the classroom teaching based on the network environment, such as "teachers 'pre-class preparation - students' independent learning and use learning feedback and assessment - answering and skill training" and we also point out the problems in implementing.

Keywords: network environment, college English teaching, flip classroom, teaching design

\section{The teaching situation and existing problems of college English}

Since the beginning of the 21 st century, college English teaching has undergone two rounds of reforms in 2002 and 2007 under the leadership of the Department of Higher Education of the Ministry of Education. The application of network and multimedia technology has great influence on the transformation of college English teaching model. The establishment of network teaching platform, the use of publishing house learning and teaching software greatly enriched the school teaching resources, and some colleges and universities use the mode of "classroom face-to-face teaching + network autonomous learning", which makes
\end{abstract}


students' individualized English learning possible. The ability of students to learn independently reflects the learner-centred modern educational thoughts.

However, under the environment of network teaching, autonomous learning of college English in the actual implementation process, "(students) learning results did not meet the expectations of network teaching reform" [1]. (1) Some teachers are not fully aware of the students' self-regulated learning on the Internet, and "self-regulated learning on the Internet" is equivalent to "students' own learning", and cannot "design specific teaching tasks according to students' characteristics" (2) the overlapping of e-learning courseware and paper-based teaching materials, the repeated teaching of teachers in the classroom, it is difficult to meet the learning needs of students to learn, the lack of learning objectives, the lack of time learning, (3) limited by the hours and energy constraints, teachers for students in the after-school network test (1), the students in the classroom after the class test, the students' And language skills practice and other problems encountered in the process of sublimation and difficulties cannot be timely guidance, problem-solving lag the students to reduce the effectiveness of learning. Therefore, although "the majority of students agree with the reform of college English teaching network and support attitude, the effect of network teaching reform negative attitude" [3].

In summary, it is not difficult to see the status quo of college English teaching problems mainly related to teachers on the network of English teaching awareness, classroom teaching content and learning resources to deal with the relationship between learning and feedback to respond to three aspects. In order to improve the teaching effect, the teachers should set up the correct teaching view besides the teaching method and the teaching content, the teaching management aspect to carry on the transformation. The inverted classroom, which is characterized by the reversal of knowledge transfer and the sequence of knowledge internalization, has certain advantages in playing the advantages of online education resources and students' learning initiative, and can provide reference for the reform of college English teaching.

\section{The connotation, origin and research status of flipping classroom}

Flip-up classroom, also known as "flipped classroom", is a new teaching model that transforms the role of teachers and students in traditional teaching and replans the use of classroom time through the arrangement of knowledge transfer and internalization of knowledge. One kind of classroom teaching content through the network learning resources platform and the interaction, take the learner individualized study as the centre, with the classroom teacher and student together constructs the knowledge community learning paradigm.

In 2007, Jonathan Bergmann and Aaron Sams, two chemistry teachers at Woodland Park High School in Colorado, uploaded live video and PPT presentations to the network for students to complete their assignments in class 
and had difficulty learning Students to explain, this is the embryonic form of flip class. At the 2011 TED conference, Salman Khan, a Bangladeshi-American scholar, reported on the use of math videos provided by Khan Academy for students to learn after class, and the flip-flop began to educate more educators.

Thanks to the support of MIT OCW, Khan Academy Video, Yale Open, and TED Education Channel video, the flip-flop has flourished. At present, the United States has become the popular innovative teaching model, in a number of cities in primary and secondary schools to carry out mathematics, science and other science curriculum reform experiments. Other countries and regions have also tried to carry out experimental research on flip-flop teaching from all levels of education.

\section{The theoretical basis of implementing flip classroom teaching of college English}

The Guidelines for College English Teaching (Draft for Consultation) published in December 2014 by the Steering Committee on College English Teaching by the Ministry of Education suggested that "universities should make full use of information technology to create a diverse teaching and learning environment, encourage teachers to construct and use Micro-lessons, Mu course, the use of quality online education resources cover the expansion of teaching content, the implementation of classroom-based online classroom and on-line courses such as teaching the blending of the students in the active learning, self-learning and personalized learning " College English flip classroom is a combination of information technology and teaching model, is the network learning and face-toface learning the right combination of hybrid learning model, its emergence in line with constructivist learning theory and mastery of learning theory.

\subsection{The constructivist learning theory}

Constructivism advocates learner-centred learning under the guidance of the teacher, believing that the real knowledge is the understanding of the external world constructed on the basis of the learner's own experience. Learning is the process of the learner's active construction. Only by choosing and processing external information and connecting with the information already existed in the brain can the students construct and perfect the knowledge system and realize the internalization of knowledge. Traditional English teaching due to limited time in the classroom, teachers can not cover the text teaching and language use of two links, so focus on classroom knowledge transfer, in order to layout the homework to review the consolidation approach requires students to independently complete the knowledge. Students encounter difficulties in time to get the timely help of teachers, teaching feedback is seriously lagging behind. With the aid of the network learning platform, the transfer of knowledge to extracurricular activities is carried out by the students themselves. 


\subsection{Master the learning theory}

Bloom's mastery of learning theory suggests that any student can have complete control of the entire learning process as long as they have the necessary conditions for learning. Its essence lies in group teaching and is complemented by the frequent feedback and individualized correctional assistance required by each student. In his view, the impact of student learning there are three main variables: the state of cognitive preparation, emotional state and teaching quality. Among them, teaching quality includes four elements: clues, participation, strengthening and feedback - correction. Cue refers to the teaching of students in the learning content and learning behaviour of the instructions; participation is in the classroom teaching, the students provided by the teaching of learning or memory content clues to make appropriate response; reinforcement refers to teachers through a variety of ways To give students incentives and praise; feedback correction refers to the teacher through the test diagnosis of students not mastered the learning content, timely feedback, to provide students with specific methods to correct errors.

\section{The instructional design of college English flipping classroom}

College English is the knowledge and skills of both course, in the teaching process only to consolidate the knowledge and skills to expand the organic combination of the learners can truly realize the knowledge and practical application. According to the teaching philosophy of flip classroom and referring to the teaching methods of flip-flop and peer-to-peer teaching proposed by Dr. Eric Mazur of Harvard University, the author believes that the instructional design of college English flip-flop classroom based on network environment can be "pre-teacher preparation - self- Learning feedback and assessment - Q \& A in the class and skills to practice "process.

\subsection{The teachers' preparation before class}

Teachers of pre-class preparation, including the learning objectives of the unit, focus on learning content, learning tasks, as well as the layout of the supplementary teaching courseware and video production. Pre-class preparation should be released in advance to the students and the purpose is to enable students to self-study extra-curricular network has a clear language and knowledge of learning objectives. According to the "College English Teaching Requirements" published by the Ministry of Education in 2007: "College English teaching should follow the principles of class instruction and teaching students according to their aptitude." ... ensure that students of different levels are adequately trained and improved in English proficiency. Teachers in the preparation of the work should take full account of the actual level of language teaching classes and future career goals, differences in the use of language, set different levels of learning goals and language skills development tasks, students 
Autonomy to choose. College English teachers in the design of teaching tasks, should refer to Bloom and other psychologists put forward the classification of teaching objectives in the theoretical system of cognitive areas of the target classification level (ie, remember, understand, use, analysis, synthesis and evaluation) From simple to complex, hierarchical design learning tasks.

\subsection{Students' independent study and application}

Students' extra-curricular network autonomous learning should be task-driven and problem-oriented learning. At this stage, students' main task is to understand the cultural background knowledge, language knowledge points and chapter structure through the various teaching resources provided by the network learning platform through various mobile terminals or network classrooms. In order to ensure the learning effect, students in addition to complete the required length of online self-learning, but also complete the text comprehension exercises, through the network learning platform unit testing to detect learning effects.

\subsection{Learning feedback and evaluation}

After completing the task and test, students can know the typical learning situation of different classes in this unit by assessing the test results and errors and the typical questions of the feedback from the learning group leader, assessing the learning effect and diagnosing the problem. From the number and nature of the problem to collect the line to determine the classroom face-to-face when the discussion is based on the discussion of the problem-based classroom or language skills development-oriented inquiry-based classroom, to be carried out in the classroom face-to-face content, design activities, Adjustments to prepare for classroom face-to-face. In addition, the teacher should also record the student's learning record, the completion of the completion of one by one registration of courses, the establishment of e-learning files, as the end of the learning evaluation of students based on.

\subsection{Q \& A and skill training}

Through feedback and assessment of students 'learning situation, teachers have a preliminary understanding of the problems existing in the students' autonomous learning, and have a clear understanding of the type and content of classroom instruction. For question-answering, discussion-based discussion of the classroom, teachers should initiate the way to guide students to solve the language knowledge difficult or have a common problem of controversy. The group's debate on the debate is not only conducive to the mobilization of learning atmosphere, but also allows everyone the opportunity to participate. In the process of discussion, teachers should pay attention to the direction of the discussion of the guide to avoid deviation from the theme. After the discussion, the problem should be further combed and summarized, to deepen students' understanding. For an inquiry-based classroom with language skills development, classroom time should be based on students' language practice activities, such as 
dialogue, discussion, theme writing, etc. The teacher can organize student or study group to give oral report or written report in the form of the presentation of the completion of communicative tasks, and the development of evaluation rules and review rules to encourage peer assessment. On the outstanding learning outcomes can be considered uploaded to the e-learning platform, to achieve resource sharing, so that students understand the sense of accomplishment of learning.

\section{The implementation recommendations of college English flipping classroom}

The network learning environment provides a convenient and flexible learning platform for the implementation of college English flip-flop classroom. However, whether it can be carried out by the students, teachers and school management level, the following should be done in practical operation:

\subsection{The dual support of study and psychological for students}

The implementation of flip - flop requires learner's high degree of participation. The learner's autonomous learning ability is the key factor for the success of college English teaching. For the students who have weak English foundation and poor computer skills, the first thing to overcome is the learning anxiety. For such students, English teachers should not only focus on learning methods and network use skills, but also in psychological counselling, the implementation of humane care, to avoid their acquisition of helplessness, to help them self-learning ability Of the gradually develop.

\subsection{The cooperation among teachers, schools and parents}

The key prerequisites for the effective implementation of the college English flip - flop are: extracurricular activities have taken place in - depth. After completing the self - study using the E - learning platform, the students should master the new knowledge to a deeper understanding level, rather than stay in the simple preview level. A good network learning environment, a short wonderful teaching video, scientific and reasonable remote visual monitoring system to ensure the effectiveness of students' online learning and quality, access to student learning real information and timely inspection and coordination has a crucial role.

\subsection{The flexible use of evaluation mechanisms}

It is not only the English learning ability of the students, but also the ability of expression, organization, cooperation, time management, etc., Which is based on the network environment. Therefore, in the learning evaluation of students should be used to formative evaluation and the end of the combined evaluation of the method, the implementation of diversity assessment. It is necessary to consider 
the students' comprehensive application of language skills, but also through a variety of activities inside and outside classes, learning archives, extra-curricular self-learning records, teacher diary and other students to evaluate the whole process of learning English to enable students to objectively understand their own learning Performance and capacity development, learn from each other, to follow the direction of learning.

\section{Conclusion}

As a new teaching mode, the college English classroom teaching is not a denial of the previous "face-to-face teaching and network autonomy" mode, but a deepening and use of teacher-led, student-centred learning concept, the success for latter has laid a good foundation for the use of flipping classroom in the college English teaching based on net environment. It is believed that with the deepening of the concept and practice of teaching reform, the advantages of flip flop teaching in college English teaching will be further revealed.

\section{Acknowledgements}

This paper is supported by the project of "Special Funds for Young and Middleaged Teachers Visiting Scholars of Development Program in Universities of Jiangxi Province", and it is the stage result of the 12th Five-year Plan Education Science Project in Jiangxi Province, "Study on the Relationship between Learning Environment and Learners' Efficacy of College English Flipping Class (15ZD3LYB032).

\section{References}

[1] Liu Yumei, Yin Manfen. Research on $2+2$ College English Teaching Models in Local Colleges - Taking Dali University as an Example. Coal Education, 55(12), pp.68-70, 2011

[2] Wang Shouren. Promoting and Implementing the Reform of College English Teaching - A Revision of the Requirements of College English Teaching (Trial), Chinese Foreign Language, 8 (5), pp.87- 91, 2013

[3] Zhai Xuesong, Lin Lilan. Analysis on the Influencing Factors of Learner Satisfaction in Flip-up Classroom: An Empirical Study Based on College English Teaching. Audio-Visual Education, 12(10), pp. 18- 20, 2012

[4] Shiquan Quan. Network security protocol in the role of computer communication technology and significance. China Building Materials Science and Technology, 9(6), pp.58- 61, 2011

[5] (Department of Higher Education, Ministry of Education, Beijing 100083, China); Requirements of College English Teaching. Beijing: Tsinghua University Press, pp.85-87, 2007 